\title{
Staging of idiopathic pulmonary fibrosis: past, present and future
}

\author{
Martin Kolb ${ }^{1}$ and Harold R. Collard ${ }^{2}$
}

Affiliations: 'Dept of Medicine, Firestone Institute for Respiratory Health, St. Joseph's Healthcare, McMaster University, Hamilton, ON, Canada. ${ }^{2}$ Dept of Medicine, Division of Pulmonary, Critical Care Medicine, Sleep and Allergy, University of California, San Francisco, CA, USA.

Correspondence: Harold R. Collard, Dept of Medicine, Division of Pulmonary, Critical Care Medicine, Sleep and Allergy, University of California, 505 Parnassus Ave, San Francisco, CA 94143, USA.

E-mail: hal.collardducsf.edu

ABSTRACT Idiopathic pulmonary fibrosis (IPF) is traditionally staged with terms such as "mild", "severe", "early" and "advanced" based on pulmonary function tests. This approach allows physicians to monitor disease progression and advise patients and their families. However, it is not known if the stages of this model reflect distinct biological or clinical phenotypes and the therapeutic and prognostic value of this system is limited.

Novel methods of IPF staging have recently been developed. The GAP model includes four baseline variables that were found to be predictive of outcome, as identified by logistic regression. These factors are: gender $(\mathrm{G})$, age $(\mathrm{A})$ and two lung physiology variables $(\mathrm{P})$ (forced vital capacity and diffusing capacity of the lung for carbon monoxide). The clinical utility and accuracy of staging models may be further improved in the future by the integration of dynamic parameters that can be measured over time, as well as biological data from biomarkers which may be able to directly measure disease activity. The development of an evidence-based, multidimensional IPF staging model that builds on the current staging approaches to IPF is an important objective for improving the management of IPF.

0

@ERSpublications

Development of an evidence-based, multidimensional IPF staging model is important for improving IPF management http://ow.ly/vyNSG

\section{Introduction}

The median survival of patients with idiopathic pulmonary fibrosis (IPF) ranges from 2.5 years to 3.5 years [1]. However, the clinical course of disease can vary considerably, from slow progression over many years to acute exacerbation, rapid loss of lung function and early death [2-4]. A number of studies have shown that selected features commonly observed in clinical practice are associated with an increased risk of mortality. These include clinical history and physical examination, as well as radiographic, physiological, pathological and biomarker findings [3]. However, there is no widely accepted, standardised method to combine such predictors in order to define prognosis or stage of disease.

\section{The importance of staging in disease management}

In general, staging systems for patients with a particular disease aim to define a classification schema that is practical, informs prognosis and impacts choice of therapeutic modality [5]. Staging systems are widely used in other diseases for guiding management decisions, with examples including those used in lung cancer [6], HIV/AIDS [7] and chronic obstructive pulmonary disease (COPD) [8]. In COPD, for example, the

Received: March 112014 | Accepted after revision: April 022014

Conflict of interest: Disclosures can be found alongside the online version of this article at err.ersjournals.com

Provenance: Publication of this peer-reviewed article was sponsored by InterMune International AG, Muttenz, Switzerland (article sponsor, European Respiratory Review issue 132).

Copyright OERS 2014. ERR articles are open access and distributed under the terms of the Creative Commons Attribution Non-Commercial Licence 4.0. 
TABLE 1 Mortality risk scoring system for patients with idiopathic pulmonary fibrosis

Risk factors

Score

$\begin{array}{lr}\text { Age years } & 8 \\ \geqslant 70 & 4 \\ 60-69 & 0 \\ <60 & \\ \text { Recent respiratory hospitalisation } & 14 \\ \text { Yes } & 0 \\ \quad \text { No } & \\ \text { Baseline FVC \% predicted } & 18 \\ \leqslant 50 & 13 \\ 51-65 & 8 \\ 66-79 & 0 \\ \geqslant 80 & \\ 24-\text { week change in FVC \% predicted } & 21 \\ \leqslant-10 & 10 \\ -5 \text { to }-9.9 & 0 \\ >-4.9 & 0\end{array}$

FVC: forced vital capacity. Sum the individual scores corresponding to the level of each risk factor for a given patient, e.g. the total score for a patient aged 70 years, with no history of respiratory hospitalisation, FVC $51-65 \%$ predicted, and a 24 -week change in FVC of -5 to $-9.9 \%$ predicted is $8+0+13+10=31$. Reproduced with modification from [21] with permission from the publisher.

Global Initiative for Chronic Obstructive Lung Disease (GOLD) staging system categorises severity of disease into four stages based on forced expiratory volume in $1 \mathrm{~s}$. Mortality risk rises with increasing stage, and treatments are added as patients progress from one stage to the next $[8,9]$.

Staging IPF is widely acknowledged to be an important goal as it: 1) would allow clinicians to use standardised nomenclature in daily practice; and 2) would guide treatment options and facilitate patient counselling. For IPF, several baseline features of the disease may be useful in staging including age, level of dyspnoea, forced vital capacity (FVC), diffusing capacity of the lung for carbon monoxide (DLCO), desaturation during the 6-min walk test, extent of honeycombing on high-resolution computed tomography (HRCT), or presence of pulmonary hypertension or emphysema [1]. Longitudinal factors such as increase in level of dyspnoea, decrease in FVC over time, decrease in DLCO or worsening of fibrosis on HRCT have also been recommended [1]. Importantly, for any staging system to be useful in daily practice, it must be simple and reproducible.

Traditional approaches to staging IPF: mild, moderate and severe

Traditionally, terms such as "mild", "moderate", "severe", "early" and "advanced” have been used to loosely stage IPF. These stages have been primarily based on pulmonary function test results. Several pulmonary

TABLE 2 Expected 1-year probability of death in patients with idiopathic pulmonary fibrosis

Total risk score

\begin{tabular}{lc}
\hline $\mathbf{0 - 4}$ & $<2$ \\
$\mathbf{8}-14$ & $2-5$ \\
$\mathbf{1 6 - 2 1}$ & $5-10$ \\
$\mathbf{2 2 - 2 9}$ & $10-20$ \\
$\mathbf{3 0 - 3 3}$ & $20-30$ \\
$\mathbf{3 4 - 3 7}$ & $30-40$ \\
$\mathbf{3 8 - 4 0}$ & $40-50$ \\
$\mathbf{4 1 - 4 3}$ & $50-60$ \\
$\mathbf{4 4 - 4 5}$ & $60-70$ \\
$\mathbf{4 7 - 4 9}$ & $70-80$ \\
$>\mathbf{5 0}$ & $>80$
\end{tabular}

The total points from table 1 are used to calculate the expected 1-year probability of death, e.g. a patient with a total risk score of 31 has a predicted 1 -year probability of death of $20-30 \%$. Reproduced with modification from [21] with permission from the publisher. 
TABLE 3 The GAP (gender, age and physiology) index

Predictor

Points

\begin{tabular}{ccc}
\hline G & Gender & \\
& Female & 0 \\
& Male & 1 \\
\hline $\mathbf{A}$ & Age years & \\
& $\leqslant 60$ & 0 \\
& $61-65$ & 1 \\
& $>65$ & 2 \\
\hline Physiology & \\
& FVC $\%$ predicted & \\
& $>75$ & 0 \\
& $50-75$ & 1 \\
& $<50$ & 2 \\
& DLco \% predicted & \\
& $>55$ & 0 \\
& $36-55$ & 1 \\
& $\leqslant 35$ & 2 \\
\hline
\end{tabular}

Maximum possible points=8. FVC: forced vital capacity; DLCO: diffusing capacity of the lung for carbon monoxide.

function values have been associated with prognosis and are believed to reflect disease severity and/or progression, most reliably FVC and DLCO [10-13]. While there is no standardised definition for mild, moderate and severe disease, clinical trials have generally agreed on a FVC threshold of 50-55\% predicted and a DLCO threshold of $35-40 \%$ pred to separate mild-to-moderate patients from those with severe disease [14-20]. This approach to staging provides physicians with a general framework to monitor disease progression and advise patients. Certain stages in the current model are used to guide treatment; for example, in several countries pirfenidone is indicated for patients with mild-to-moderate IPF, while lung transplantation is considered in severe IPF.

\section{Limitations of the traditional approach to IPF staging}

While the traditional approach to IPF staging has been useful, it is arbitrary and is not based on epidemiological or biological data. It remains unclear if these stages are truly relevant to the management of IPF. Critically, these traditional stages are not known to reflect distinct biological or clinical phenotypes and the true therapeutic and prognostic relevance of these stages remains undetermined.

IPF does not progress in a linear pattern and using baseline physiological parameters, such as FVC, alone probably oversimplifies the staging process. As mentioned previously, a number of studies have shown that selected features of IPF, which are commonly observed in clinical practice, are associated with an increased risk of mortality [3]. Incorporation of these factors into a multidimensional staging model may enhance the validity and clinical applicability of staging in IPF, but requires validation.

\section{Novel IPF staging systems}

Several groups have provided multivariate models that attempt to provide a basis for a more sophisticated approach to staging of IPF. Using a large clinical trial population of patients with IPF, DU BoIs et al. [21] developed a scoring system comprised of four predictors: age, recent respiratory hospitalisation, baseline

\section{TABLE 4 The GAP (gender, age and physiology) index and staging system}

\begin{tabular}{lccc} 
Stage & I & II & III \\
Points & $0-3$ & $4-5$ & $6-8$ \\
Mortality years & & & \\
1 & 5.6 & 16.2 & 39.2 \\
2 & 10.9 & 29.9 & 62.1 \\
3 & 16.3 & 42.1 & 76.8 \\
\hline
\end{tabular}


FVC and 24-week change in FVC. As shown in table 1, the sum of individual scores for the four parameters are used to obtain a composite score that can accurately predict the 1-year risk of death (table 2).

More recently, LEY et al. [22] developed a multidimensional risk prediction model and staging system using data from three large, geographically distinct cohorts of IPF patients in California (USA), Minnesota (USA) and Northern Italy. This GAP model consists of four baseline variables: gender (G), age (A) and two lung physiology variables (P) (FVC and DLCO). A regression model using continuous predictors (GAP calculator) and a simplified scoring system (GAP index) (table 3) were developed (www.acponline.org/ journals/annals/extras/gap). Three stages, I, II and III, were identified based on the GAP index with 1-year mortalities of $6 \%, 16 \%$ and $39 \%$, respectively (table 4). It was proposed that the GAP index and staging system be used as a quick and simple screening method for estimating risk in patients with IPF; the GAP calculator can then be used to estimate the individual risk for patients in whom a more precise estimate may affect clinical decisions.

\section{Future directions}

As highlighted previously, it will also be important in future staging systems to integrate baseline information with longitudinal parameters such as changes in dyspnoea and categorical decline in FVC of $\geqslant 10 \%$ pred, both of which are strong dynamic predictors [23]. Visual scoring of the extent of fibrosis on HRCT at baseline and over time may also be valuable in staging disease [24]. Moving forward, probably the greatest need in staging is the integration of biological data and the inclusion of this data offers the greatest potential improvements. Aggressive development of molecular and other biological biomarkers is just beginning, and additional work in this area is greatly needed. Markers being investigated include serum markers, such as KL-6, surfactant protein (SP)-A/D, CCL18, brain natriuretic peptide and matrix metalloproteinase-7, and markers from bronchoalveolar lavage, such as SP-A and neutrophilia [25, 26].

Ultimately, the development of improved staging systems in IPF requires balancing of two key priorities: 1) identifying the most accurate predictors of IPF prognosis; and 2) determining a practical and clinically useful method with which to integrate these parameters.

\section{Conclusion}

Staging systems offer important benefits to medical practice and clinical trial design. Traditional approaches to staging in IPF using mild, moderate or severe classifiers based on baseline pulmonary physiology leave substantial room for improvement and should be replaced by more integrative and evidence-based methods. Improved staging of IPF would allow clinicians to use standardised nomenclature for medical practice, enable better definition of clinical trial populations and end-points, guide treatment options and enhance patient counselling. We hope that the IPF community can develop a standard evidence-based approach to staging that can then be improved as new knowledge of disease biology, IPF phenotypes and behaviour emerges.

Undoubtedly, our increasing understanding of IPF pathophysiology will result in more sophisticated IPF staging systems, which will better inform the management of this devastating condition.

\section{Acknowledgements}

This article is based on the proceedings of the 2013 Advancing IPF Research (AIR) meeting (Nice, France), which was sponsored by InterMune International AG (Muttenz, Switzerland). Medical writing support was provided by Michael Smith (IntraMed International, Milan, Italy), which was funded by InterMune International AG.

\section{References}

1 Raghu G, Collard HR, Egan JJ, et al. An official ATS/ERS/JRS/ALAT statement: idiopathic pulmonary fibrosis: evidence-based guidelines for diagnosis and management. Am J Respir Crit Care Med 2011; 183: 788-824.

2 Fernandez Perez ER, Daniels CE, Schroeder DR, et al. Incidence, prevalence, and clinical course of idiopathic pulmonary fibrosis: a population-based study. Chest 2010; 137: 129-137.

3 Ley B, Collard HR, King TE Jr, et al. Clinical course and prediction of survival in idiopathic pulmonary fibrosis. Am J Respir Crit Care Med 2011; 183: 431-440.

4 Collard HR, Moore BB, Flaherty KR, et al. Acute exacerbations of idiopathic pulmonary fibrosis. Am J Respir Crit Care Med 2007; 176: 636-643.

5 Gonnella JS, Hornbrook MC, Louis DZ. Staging of disease. A case-mix measurement. JAMA 1984; 251: 637-644.

6 Goldstraw P. International Association for the Study of Lung Cancer Staging Manual In Thoracic Oncology. 1st Edn. Orange Park, Editorial Rx Press, 2009.

7 World Health Organization. WHO case definitions of HIV for surveillance and revised clinical staging and immunological classification of HIV-related disease in adults and children. Geneva, WHO, 2007.

8 Global Initiative for Chronic Obstructive Lung Disease. Global strategy for the diagnosis, management, and prevention of chronic obstructive pulmonary disease. 2013. www.goldcopd.org/uploads/users/files/GOLD Report_2013_Feb20.pdf Date last updated: December 2013. Date last accessed: January 17, 2014. 
Ekberg-Aronsson M, Pehrsson K, Nilsson JA, et al. Mortality in GOLD stages of COPD and its dependence on symptoms of chronic bronchitis. Respir Res 2005; 6: 98.

10 Collard HR, King TE Jr, Bartelson BB, et al. Changes in clinical and physiologic variables predict survival in idiopathic pulmonary fibrosis. Am J Respir Crit Care Med 2003; 168: 538-542.

11 Flaherty KR, Mumford JA, Murray S, et al. Prognostic implications of physiologic and radiographic changes in idiopathic interstitial pneumonia. Am J Respir Crit Care Med 2003; 168: 543-548.

12 Latsi PI, du Bois RM, Nicholson AG, et al. Fibrotic idiopathic interstitial pneumonia: the prognostic value of longitudinal functional trends. Am J Respir Crit Care Med 2003; 168: 531-537.

13 King TE Jr, Tooze JA, Schwarz MI, et al. Predicting survival in idiopathic pulmonary fibrosis. Scoring system and survival model. Am J Respir Crit Care Med 2001; 164: 1171-1181.

14 Noble PW, Albera C, Bradford WZ, et al. Pirfenidone in patients with idiopathic pulmonary fibrosis (CAPACITY): two randomised trials. Lancet 2011; 377: 1760-1769.

15 Richeldi L, Costabel U, Selman M, et al. Efficacy of a tyrosine kinase inhibitor in idiopathic pulmonary fibrosis. N Engl J Med 2011; 365: 1079-1087.

16 King TE Jr, Behr J, Brown KK, et al. BUILD-1: a randomized placebo-controlled trial of bosentan in idiopathic pulmonary fibrosis. Am J Respir Crit Care Med 2008; 177: 75-81.

17 King TE Jr, Brown KK, Raghu G, et al. BUILD-3: a randomized, controlled trial of bosentan in idiopathic pulmonary fibrosis. Am J Respir Crit Care Med 2011; 184: 92-99.

18 Idiopathic Pulmonary Fibrosis Clinical Research Network, Raghu G, Anstrom KJ, et al. Prednisone, azathioprine, and $N$-acetylcysteine for pulmonary fibrosis. N Engl J Med 2012; 366: 1968-1977.

19 Mogulkoc N, Brutsche MH, Bishop PW, et al. Pulmonary function in idiopathic pulmonary fibrosis and referral for lung transplantation. Am J Respir Crit Care Med 2001; 164: 103-108.

20 Egan JJ, Martinez FJ, Wells AU, et al. Lung function estimates in idiopathic pulmonary fibrosis: the potential for a simple classification. Thorax 2005; 60: 270-273.

21 du Bois RM, Weycker D, Albera C, et al. Ascertainment of individual risk of mortality for patients with idiopathic pulmonary fibrosis. Am J Respir Crit Care Med 2011; 184: 459-466.

22 Ley B, Ryerson CJ, Vittinghoff E, et al. A multidimensional index and staging system for idiopathic pulmonary fibrosis. Ann Intern Med 2012; 156: 684-691.

23 Best AC, Meng J, Lynch AM, et al. Idiopathic pulmonary fibrosis: physiologic tests, quantitative CT indexes, and CT visual scores as predictors of mortality. Radiology 2008; 246: 935-940.

24 Battista G, Zompatori M, Fasano L, et al. Progressive worsening of idiopathic pulmonary fibrosis. High resolution computed tomography (HRCT) study with functional correlations. Radiol Med 2003; 105: 2-11.

25 Richards TJ, Kaminski N, Baribaud F, et al. Peripheral blood proteins predict mortality in idiopathic pulmonary fibrosis. Am J Respir Crit Care Med 2012; 185: 67-76.

26 Zhang Y, Kaminski N. Biomarkers in idiopathic pulmonary fibrosis. Curr Opin Pulm Med 2012; 18: $441-446$. 